the change in the conditions of award whereby the Kalinga Prize now becomes a mark of recognition for "a distinguished career of public service in the interpretation of science". It is interesting that the nomination which brought Mr. Kaempffert's name before this year's judges came from the Association of British Science Writers, which exists to improve the standards of science writing in Great Britain. Mr. Kaempffert's views on the present state of the press relations of science were vigorously expressed in a recent number of the Bulletin of the Atomic Scientists (November 1953) in an article headed "Neither is Perfect".

\section{Department of Genetics of the University of Sheffield}

THE recent establishment of a separate Department of Genetics in the University of Sheffield is the logical development of the stimulus given to this subject in the Departments of Botany and Zoology when Dr. J. M. Thoday was appointed as lecturer in cytogenetics in 1947. In addition to the immediate impact of the teaching of genetics on the two parent Departments, the subject has an increasing importance in shedding new light on biological problems at all levels. This has been emphasized by courses given in medical and microbiological departments and by the steady growth of a thriving research school. 'The independence accorded to genetics in Sheffield now makes possible extensions into wider fields without interfering with the teaching of genetics as hitherto to students of botany and zoology. While Dr. Thoday's research interests are varied, they have perhaps expressed themselves most prominently in investigating the effects of ionizing radiations on chromosome structural changes and the further influence of environmental factors on the frequency of these changes. In setting up the new Department, the University has recognized the rightful independence of a subject which cuts across the formal frontiers of long-standing subjects like anatomy, botany, physiology and zoology. That it has been thought fit to appoint Dr. Thodary as senior lecturer in charge is a testimony to his ingenuity as a research worker, his inspiration as a teacher and his insight as a supervisor of research.

\section{Centenary of Boole's "The Laws of Thought"}

The centenary of the publication of the "Laws of Thought" by George Boole was celebrated at the Royal Irish Academy, Dublin, during May 24-25. The "Laws of Thought" was published in 1854 while Boole was professor of mathematics in Queen's College, Cork; but his association with the Royal Irish Academy had begun ten years earlier when his friendship with the Rev. Charles Graves led him to use the Proceedings and Transactions of the Acadomy as a medium for the publication of some of his papers. At the recent meeting in Dublin the guests included Prof. L. E. J. Brouwer (Blaricum, Holland), 'T. T. Craven (Automatic Telephone Co., Liverpool), W. C. Kneale (Exeter College, Oxford), Rush Rhees (University College, Swansea), Prof. J. B. Rosser (Cornell University), Sir Geoffrey Taylor, and the Rev. Ivo Thomas (Hawkesyard Priory, Staffs). The afternoon of May 24 was devoted to a formal celebration, when Sir Geoffrey Taylor, a grandson of Boole, spoke on George Boole and his family connexions, and the Rev. Canon Feys gave an address entitled "Boole's Achievement in Developing Symbolic Logic". On the morning of each day there was a technical session at which the following papers were read: F. E. Hackett, the Method of George Boole; J. B. Rosser, Boole and the Concept of Function ; T. L. Craven, Boolean Algebra and Switching Current Design; Rev. Ivo 'Thomas, Boole's Concept of Science; Rev. Canon Feys, Boole's Technique in the "Laws of Thought"; Michael MacConaill, the Likeness of Correlated Relations ; and L. E. J. Brouwer, the Effect of Intuitionism on the Classical Algebra of Logic. These papers will be published in a special issue of the Proceedings of the Academy.

\section{Artificial Stimulation of Rain}

Is the House of Commons on June 15, Mr. Geoffrey de Freitas asked the Under-Secretary for Air whether the physical sub-committee of the Meteorological Research Committee had yet considered the problem of weather modification; and what conclusions it reached. This matter had been raised earlier by $\mathrm{Mr}$. de Freitas (see Nature, March 13, p. 474). Mr. George Ward, in a written reply, stated that the committee had recently considered this subject and come to the conclusion that there is no reliable evidenco that rainfall has ever been artificially increased on an economically useful scale, and that there is no scientific basis for believing that any method yet proposed would be successful in achieving such a result. Since there is so much at stake, however, the committee considers that scientifically conducted research should be intensified, particularly into the large-scale diffusion of airborne particles, the analyses of natural nuclei concentrations and the design of the large-scale field trials which would be necessary to test the effectiveness of the proposed methods of operation. The Meteorological Office is putting in hand the studies recommended by the sub-committee.

\section{Research and the Future of the World}

IN an address entitled "Today's Research and Tomorrow's World" to guests of the board of directors of the Stanford Research Institute at Los Angeles on January 20 (pp. 16. Washington, D.C. : Carnegie Institution of Washington, 1954), Dr. Vannevar Bush, reviewing the possibilities of atomic warfare which confront us, said that whatever the future has in store, whether an atomic war, a long stalemate or a gradual transition to a more salutary position, for the present we should, by creating strength in the free world, seek to maintain peace and postpone a fully developed impasse. One phase of this, he said, involves building an adequate defence system for the North American Continent, which at present is nearly wide open to aerial attack. This lack of balance is due chiefly to two reasons: first, it has only fairly recently, through technical advances, been possible to ensure a reasonable and economic degree of protection, sufficient to raise doubt in the mind of an enemy as to tho success of a single surprise attack; secondly, the national military planning organization is short of the sound integrated system essential for national safety. In Dr. Bush's opinion, the United States could have a defensive system which is worth while, without unduly burdening its economy or unwise sacrifice of any other element in its military preparedness, and should insist on having it and the improved military planning. After referring also to the need to make its system of democracy work and maintain vigorously some of its ideals of freedom, Dr. Bush turned to some of the trends in research and development which offer new hope. The blos- 